OPEN ACCESS

Edited by:

Yves Durandy,

Centre Chirurgical Marie

Lannelongue, France

Reviewed by:

Meena Nathan,

Boston Children's Hospital, USA

Massimo Caputo,

University of Bristol, UK

*Correspondence:

Utpal S. Bhalala

utpal.bhalala@bcm.edu

Specialty section:

This article was submitted to

Pediatric Cardiology,

a section of the journal

Frontiers in Pediatrics

Received: 26 July 2016 Accepted: 07 September 2016 Published: 28 September 2016

Citation:

Bhalala US, Appachi E and Mumtaz MA (2016) Neurologic Injury Associated with Rewarming from Hypothermia: Is Mild Hypothermia on

Bypass Better than Deep Hypothermic Circulatory Arrest?

Front. Pediatr. 4:104.

doi: 10.3389/fped.2016.00104

\section{Neurologic Injury Associated with Rewarming from Hypothermia: Is Mild Hypothermia on Bypass Better than Deep Hypothermic Circulatory Arrest?}

\author{
Utpal S. Bhalala*, Elumalai Appachi and Muhammad Ali Mumtaz \\ Children's Hospital of San Antonio, Baylor College of Medicine, San Antonio, TX, USA
}

Many known risk factors for adverse cardiovascular and neurological outcomes in children with congenital heart defects (CHD) are not modifiable; however, the temperature and blood flow during cardiopulmonary bypass (CPB), are two risk factors, which may be altered in an attempt to improve long-term neurological outcomes. Deep hypothermic circulatory arrest, traditionally used for aortic arch repair, has been associated with shortterm and long-term neurologic sequelae. Therefore, there is a rising interest in using moderate hypothermia with selective antegrade cerebral blood flow on CPB during aortic arch repair. Rewarming from moderate-to-deep hypothermia has been shown to be associated with neuronal injury, neuroinflammation, and loss of cerebrovascular autoregulation. A significantly lesser degree of rewarming is required following mild $\left(33-35^{\circ} \mathrm{C}\right)$ hypothermia as compared with moderate $\left(28-32^{\circ} \mathrm{C}\right)$, deep $\left(21-27^{\circ} \mathrm{C}\right)$, and profound (less than $20^{\circ} \mathrm{C}$ ) hypothermia. Therefore, we believe that mild hypothermia is associated with a lower risk of rewarming-induced neurologic injury. We hypothesize that mild hypothermia with selective antegrade cerebral perfusion during CPB for neonatal aortic arch repair would be associated with improved neurologic outcome.

Keywords: hypothermia, cardiopulmonary bypass, congenital heart defects, children, neuroinjury

\section{INTRODUCTION}

Congenital heart disease (CHD) is a common cause of morbidity and mortality in children. Eight in 1,000 newborns are diagnosed with CHDs, and approximately two to three million individuals are living in the US with CHDs $(1,2)$. Childhood survival with CHD has greatly improved over the decades following the first attempts at surgical intervention. Morbidity remains significant in survivors and is related to low cardiac output syndrome (LCOS), end-organ dysfunction, and neurological injury. Postoperative neurological injury increases the duration and cost of hospitalization and decreases postoperative quality of life. Neurological impairment is also linked to increased morbidity and mortality. Long-term neurocognitive outcomes in children with congenital heart disease are determined by variety of prenatal, perinatal, and postnatal factors, and some of them are not related to the surgical strategy. Cardiopulmonary bypass (CPB) surgery is a potential risk factor, which is known to contribute to the neurologic injury in this patient population. Various causative mechanisms have been postulated for neurological injury after $\mathrm{CPB}$. These include embolization of gaseous and particulate matter, cerebral hypoperfusion, and systemic inflammatory response to CPB 
$(3,4)$. Various strategies have been described to reduce or prevent the occurrence of post- $\mathrm{CPB}$ neurological injury. Temperature manipulation during $\mathrm{CPB}$ is an important variable that could affect neurological outcome after CPB. Traditionally, aortic arch anomalies are repaired using deep hypothermic $\left(18^{\circ} \mathrm{C}\right)$ circulatory arrest (DHCA) to allow for a bloodless field and adequate repair (5). However, DHCA provides a limited time for a complex repair with the potential for significant neurologic injury (6). To minimize the cerebral ischemia during DHCA, selective antegrade cerebral perfusion (SACP) has been utilized, but the results are conflicting (7-9) (Table 1). Many children's centers continue to advocate deep hypothermia at $18^{\circ} \mathrm{C}$ with selective antegrade cerebral blood flow, during neonatal aortic arch repair. However, rewarming from moderate-to-deep hypothermia is associated with loss of cerebrovascular autoregulation and neuronal injury (10-15). Hypothermic CPB is associated with abnormal cerebrovascular autoregulation that is worsened with rewarming (11). Similarly, impairment of cerebral vascular reactivity has been reported in patients with traumatic brain injury after rewarming from therapeutic hypothermia (16). Degree and rate of rewarming from hypothermia in swine model of hypoxic ischemic cardiac arrest has been associated with increased neuronal apoptosis (17). The underlying mechanism of increased vulnerability to neurologic injury during rewarming from hypothermia is unknown, but it may be related to inadvertent cerebral hyperthermia (18). Mild hypothermia for aortic arch repair in adults has been reported to be simple, safe, and effective method of organ protection (19). Therefore, some centers have adopted mild hypothermia with SACP as a standard of care during aortic arch repair in children. To date, there is no study of short-term and long-term outcomes following mild hypothermia $\left(32-35^{\circ} \mathrm{C}\right)$ with SACP in children undergoing aortic arch repair.

\section{BACKGROUND}

Survival of neonates with complex congenital heart defects (CHDs) continues to improve; however, cardiovascular and neurodevelopmental outcomes in survivors remain a concern. Neurodevelopmental impairment is the most common morbidity affecting the quality of life of children with CHD (24-26). Children who require cardiac surgery during the neonatal period have a significantly higher incidence of academic delays, motor difficulties, behavioral problems, issues with visual-motor integration and executive planning, language problems, inattention, and hyperactivity. The need for special services is significantly increased compared with the general population, as they get older (24). In a long-term follow-up study of patients with hypoplastic left heart syndrome, $30 \%$ received special education, the median IQ was 86 , and $18 \%$ had some mental retardation (26).

\section{MODIFIABLE RISK FACTORS AND OUTCOMES IN NEONATES FOLLOWING REPAIR FOR CHDs}

Many known risk factors for adverse cardiovascular and neurological outcomes in neonates with CHD are not modifiable. The temperature and perfusion during $\mathrm{CPB}$ are two risk factors, which may be altered to improve long-term neurological outcomes. The relationship between metabolic rate and temperature was first described over 60 years ago, and hypothermia has become the mainstay of cardiac and neurological organ protection during CPB $(5,25)$. The complexity of the surgery, age, clinical status, and surgeon's preference, all, determine the level of hypothermia during CPB (25). Four levels of hypothermia have been described: mild $\left(33-35^{\circ} \mathrm{C}\right)$, moderate $\left(28-32^{\circ} \mathrm{C}\right)$, deep $\left(21-27^{\circ} \mathrm{C}\right)$, and profound (less than $\left.20^{\circ} \mathrm{C}\right)(27,28)$. For correction of specific types of CHDs, CPB and DHCA are used to optimize surgical visualization and allow complex repairs in a bloodless field. DHCA is associated with delayed return of cerebral blood flow and metabolism and increased risk of seizures during postoperative period $(25,29)$. In a study where neonates were randomly assigned to either DHCA or deep hypothermic low blood flow on $\mathrm{CPB}$ during aortic arch repair, both strategies were associated with increased risk of neurodevelopmental disabilities (6). SACP allows residual cerebral metabolism, so antegrade cerebral perfusion with moderate hypothermia has become the preferred strategy for adult aortic arch surgery patients and has also been utilized in some centers for children $(19,24)$. But, the results of SACP with moderate-to-deep hypothermia during aortic arch repair have been conflicting (7-9) (Table 1). In short, neither moderate hypothermia nor deep hypothermia, despite introduction of selective cerebral perfusion (SCP), has been associated with favorable outcomes.

\section{EFFECTS OF REWARMING FROM HYPOTHERMIA}

With growing evidence suggesting deleterious effects of prolonged circulatory arrest with profound hypothermia (24),

TABLE 1 | Summary of randomized controlled trials (RCTs) comparing neurologic outcomes following deep hypothermic circulatory arrest (DHCA) and selective cerebral perfusion (SCP).

\begin{tabular}{|c|c|c|c|c|c|c|c|c|c|}
\hline \multirow[t]{2}{*}{ Study } & \multirow[t]{2}{*}{ Subjects } & \multirow[t]{2}{*}{ Surgery } & \multicolumn{2}{|c|}{ DHCA } & \multicolumn{2}{|c|}{ SCP } & \multicolumn{3}{|c|}{ Neurologic outcomes } \\
\hline & & & $\mathbf{E}$ & A & $\mathbf{E}$ & A & Short-term & Long-Term & Imaging \\
\hline Goldberg et al. (20) & Infants & Norwood surgery & 38 & 30 & 39 & 27 & Not studied & No difference & Not studied \\
\hline Algra et al. (8) & Neonates & Aortic arch repair & 19 & 18 & 18 & 18 & No difference & Not studied & No difference \\
\hline Harrington et al. (21) & Adult & Aortic arch surgery & 21 & 20 & 21 & 21 & SCP better than DHCA & No difference & Not studied \\
\hline Vuylsteke et al. (22) & Adults & Pulmonary endarterectomy & 35 & 30 & 39 & 36 & Not studied & No difference & Not studied \\
\hline Myung et al. (23) & Neonatal piglets & $\mathrm{CPB}$ with $\mathrm{DHCA} \pm \mathrm{SCP}$ & 12 & 8 & 9 & 8 & SCP better than DHCA & Not studied & Not studied \\
\hline
\end{tabular}

RCTS, randomized controlled trials; DHCA, deep hypothermic circulatory arrest; SCP, selective cerebral perfusion, E, enrolled; $A$, analyzed. 
moderate hypothermia with low flow $\mathrm{CPB}$ has been used to improve outcome. But, rewarming from moderate hypothermia has also been shown to be associated with loss of cerebral autoregulation and neuronal loss (10-15). Several animal studies suggest that even small increases in cerebral temperature $\left(1-2^{\circ} \mathrm{C}\right)$ exacerbate ischemic neuronal injury (30-37). After moderate hypothermia, rewarming to $37^{\circ} \mathrm{C}$ was associated with a significant increase in average cerebrovascular pressure reactivity index, indicating temperature-dependent hyperemic derangement of cerebrovascular reactivity (16). Increased neuronal apoptosis has been demonstrated during rewarming from hypothermia in swine model of hypoxic ischemic cardiac arrest (17). In this study, at $29 \mathrm{~h}$ after hypoxia-ischemia, rewarmed piglets showed worse neuroapoptosis in motor cortex than did those that remained hypothermic. Neuroapoptosis in piriform cortex was also worse in hypoxic-ischemic, rewarmed piglets than in naive/sham piglets. Rate of rewarming was positively correlated with worse neuronal injury (17). In a similar study, piglets that received delayed hypothermia, followed by rewarming after hypoxia-ischemia, had significantly more apoptosis in the subcortical white matter than did normothermic piglets (38). The exact mechanism of deleterious effects of rewarming on cerebrovascular autoregulation and neuronal survival is not known. It is possible that physiologic and biochemical effects of rewarming from hypothermia are similar to those of fever or hyperthermia (Figure 1). Typically, fever or hyperthermia are associated with an increase in core body temperature by $2-10^{\circ} \mathrm{C}$, whereas, restoration of normothermia from moderateto-deep hypothermia on CPB involves $10-20^{\circ} \mathrm{C}$ of rewarming. Also, in most cases, such a significant degree of rewarming from moderate-to-deep hypothermia occurs over a short period of time on CPB (Figure 2). Due to significant concerns of degree and rate of rewarming from moderate-to-deep hypothermia, it is now time to readdress the ideal temperature strategy on $\mathrm{CPB}$ during neonatal aortic arch repair.

\section{MILD HYPOTHERMIA WITH SELECTIVE ANTEGRADE CEREBRAL PERFUSION DURING NEONATAL AORTIC ARCH REPAIR}

With mild hypothermia, the degree of rewarming required is reduced as compared with more aggressive hypothermia. As a result, rewarming-induced neuroinjury may be reduced with mild hypothermia as compared with moderate-to-deep hypothermia. Some centers have adopted mild hypothermia with SACP as a standard temperature strategy during the $\mathrm{CPB}$ in neonates undergoing aortic arch repair. The short-term outcomes of mild hypothermia with SACP during neonatal aortic arch repair are unknown. Postoperative end-organ dysfunction, such as LCOS, acute kidney injury, and acute neurologic injury, determine shortterm outcomes after surgery for CHD. LCOS is one of the major causes of perioperative morbidity and mortality (39-41). Ischemiareperfusion injury, inflammation, and postoperative cytokine balance play a central role in pathophysiology of end-organ dysfunction (42-44). Cytokine balance during cardiac surgery can be modified by pharmacologic and physical interventions $(20,44)$. Moderate hypothermia during CPB increases the synthesis of antiinflammatory cytokines, blunts the release of pro-inflammatory cytokines, and provides organ protection (44). However, there is no information on the effects of mild hypothermia with SACP on proinflammatory and anti-inflammatory cytokines and end-organ function in neonates after aortic arch repair. Long-term outcomes of mild hypothermia with SACP during neonatal aortic arch repair have not been studied. Poor long-term neurodevelopmental outcome remains the major cause of morbidity and poor quality

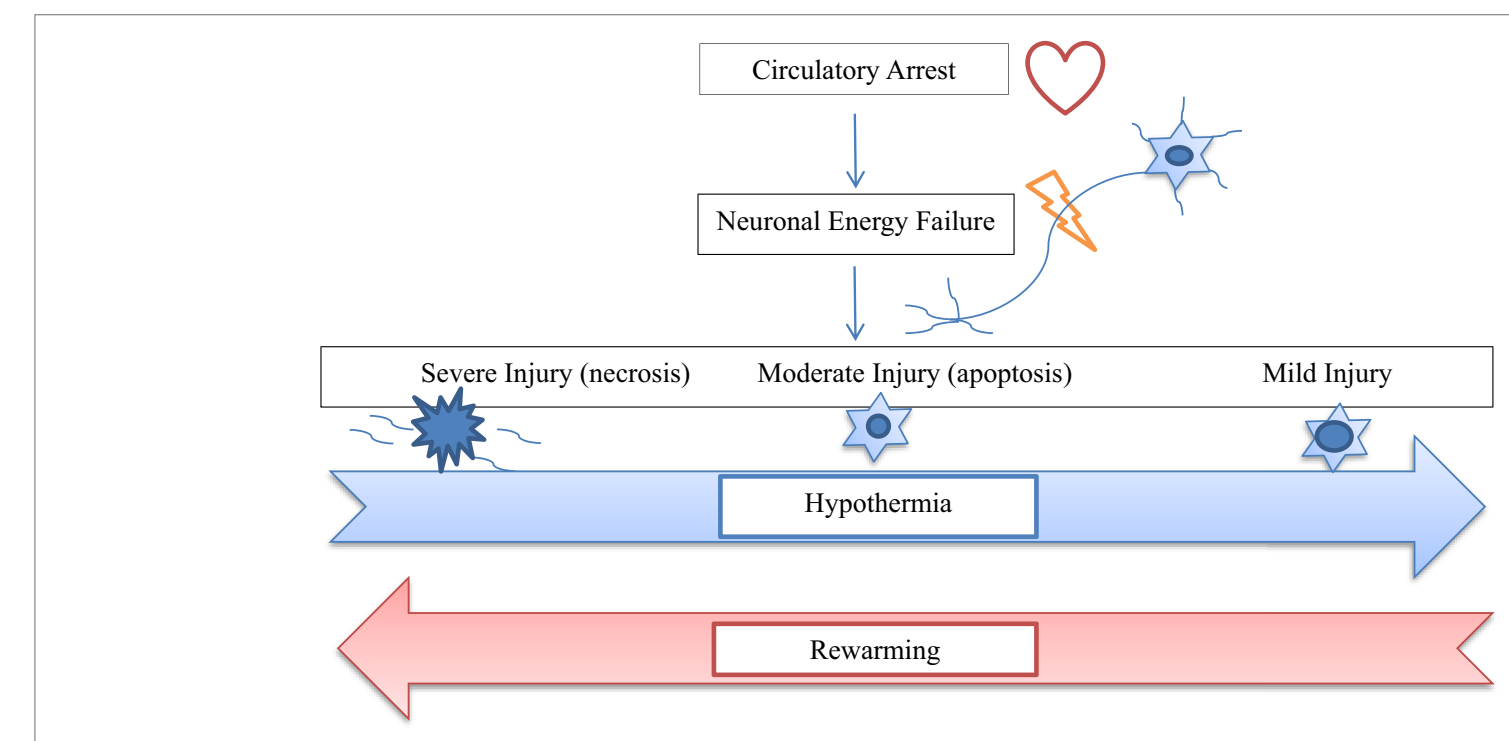

FIGURE 1 | The diagram shows relationship of hypothermia and rewarming with the spectrum of neuronal injury after circulatory arrest. Hypothermia shifts cellular injury from necrosis to apoptosis to recovery, whereas, rewarming tends to worsen the degree of neuronal injury from apoptosis to necrosis. 


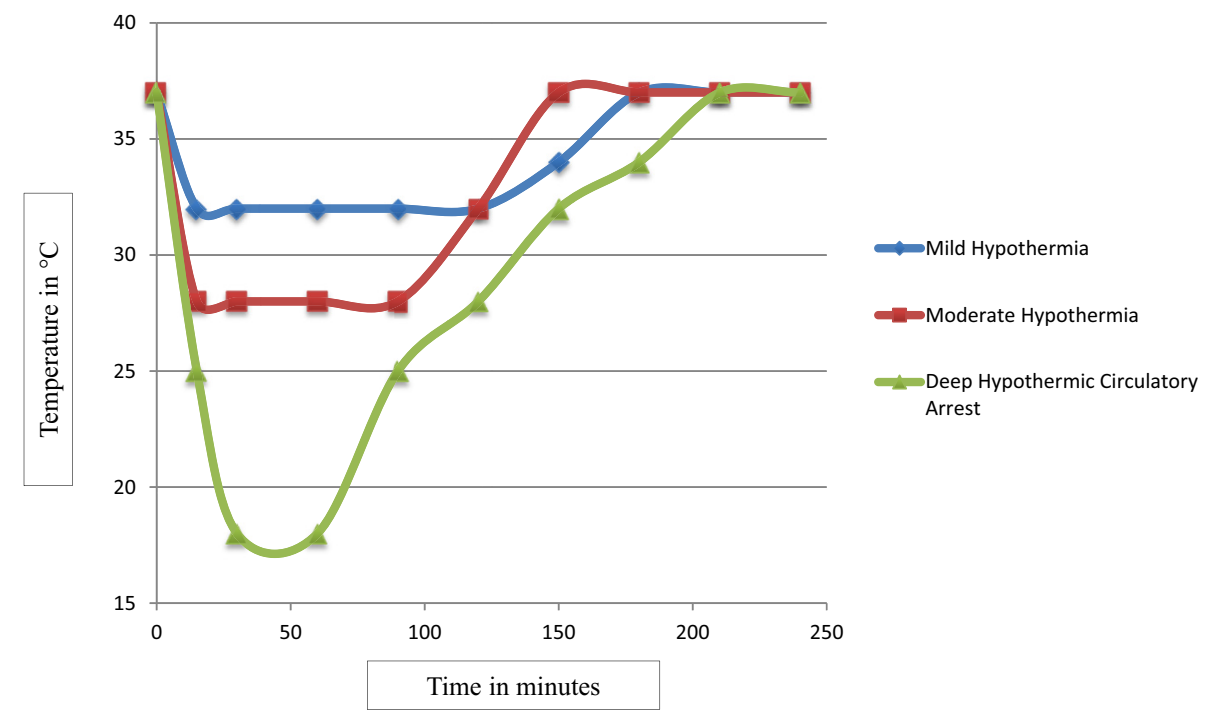

FIGURE 2 | The scatter plot of temperature changes during mild, moderate, and deep hypothermia and rewarming from each of mild, moderate, and deep hypothermia on CPB. The degree and rate of rewarming from mild hypothermia differs significantly from the degree and rate of rewarming from moderate and deep hypothermia.

of life in the neonates surviving surgical repair of CHD. Evidence to support the deleterious effects of rewarming from hypothermia raises concerns about the neuroprotective effects of moderate or deep hypothermia, during CPB. Since the degree of rewarming differs significantly between moderate/deep hypothermia and mild hypothermia, it is conceivable that mild hypothermia offers better neuroprotection. As mild hypothermia during $\mathrm{CPB}$ is being used more widely as a standard temperature strategy, it is essential to learn about its long-term neurodevelopmental effects.

\section{CONCLUSION}

Rewarming from moderate-to-deep hypothermia is associated with neuroinjury. Mild hypothermia is associated with only

\section{REFERENCES}

1. Marelli AJ, Mackie AS, Ionescu-Ittu R, Rahme E, Pilote L. Congenital heart disease in the general population: changing prevalence and age distribution. Circulation (2007) 115(2):163-72. doi:10.1161/CIRCULATIONAHA. 106.627224

2. Hoffman JI, Kaplan S, Liberthson RR. Prevalence of congenital heart disease. Am Heart J (2004) 147(3):425-39. doi:10.1016/j.ahj.2003.05.003

3. Arrowsmith JE, Grocot HP, Reves JG, Newman MF. Central nervous system complications of cardiac surgery. Br J Anaesth (2000) 84:378-93. doi:10.1093/ oxfordjournals.bja.a013444

4. Neuman MF, Grocot HP, Mathew JP, White WD, Landolfo K, Reves JG, et al. Report of the substudy assessing impact of neurocognitive function on quality of life 5 years after cardiac surgery. Stroke (2001) 32:2874-81. doi:10.1161/ hs1201.099803

5. Bigelow WG, Lindsey WK, Greenwood WF. Hypothermia: it's possible role in cardiac surgery: an investigation of factors governing survival of dogs at low body temperatures. Ann Surg (1950) 132:849-66. doi:10.1097/00000658195011000-00001 $3-5^{\circ} \mathrm{C}$ rewarming, whereas, moderate-to-deep hypothermia is associated with $10-20^{\circ} \mathrm{C}$ of rewarming to reach normothermia. Theoretically, mild hypothermia is associated with a significantly lower risk of rewarming-induced neuroinjury. It is conceivable that mild hypothermia with SACP is a rational strategy during $\mathrm{CPB}$ in neonates undergoing aortic arch repair. Short-term and long-term outcomes in children with CHDs following this newly adopted temperature strategy on $\mathrm{CPB}$ need a thorough evaluation, before it could be accepted widely.

\section{AUTHOR CONTRIBUTIONS}

All authors contributed equally to this work.

6. Wypij D, Newburger JW, Rappaport LA, duPlessis AJ, Jonas RA, Wernovsky $\mathrm{G}$, et al. The effect of duration of deep hypothermic circulatory arrest in infant heart surgery on late neurodevelopment: the Boston Circulatory Arrest Trial. J Thorac Cardiovasc Surg (2003) 126(5):1397-403. doi:10.1016/ S0022-5223(03)00940-1

7. Tian DH, Wan B, Bannon PG, Misfeld M, Lemaire SA, Kazui T, et al. A meta-analysis of deep hypothermic circulatory arrest versus moderate hypothermic circulatory arrest with selective antegrade cerebral perfusion. Ann Cardiothorac Surg (2013) 2:148-58. doi:10.3978/j.issn.2225-319X. 2013.03.13

8. Algra SO, Jansen NJ, van der Tweel I, Schouten AN, Groenendaal F, Toet M, et al. Neurological injury after neonatal cardiac surgery: a randomized, controlled trial of 2 perfusion techniques. Circulation (2014) 129:224-33. doi:10.1161/CIRCULATIONAHA.113.003312

9. Kornilov IA, Sinelnikov YS, Soinov IA, Ponomarev DN, Kshanovskaya MS, Krivoshapkina AA, et al. Outcomes after aortic arch reconstruction for infants: deep hypothermic circulatory arrest versus moderate hypothermia with selective antegrade cerebral perfusion. Eur J Cardiothorac Surg (2015) 48:e45-50. doi:10.1093/ejcts/ezv235 
10. Hori D, Everett AD, Lee JK, Ono M, Shah AS, Mandal K, et al. Rewarming rate during cardiopulmonary bypass is associate with release of glial fibrillary acidic protein. Ann Thorac Surg (2015) 100(4):1353-8. doi:10.1016/j. athoracsur.2015.04.006

11. Joshi B, Brady K, Lee J, Easley B, Panigrahi R, Smielewski P, et al. Impaired autoregulation of cerebral blood flow during rewarming from hypothermic cardiopulmonary bypass and its potential association with stroke. Anesth Analg (2010) 110(2):321-8. doi:10.1213/ANE.0b013e3181c6fd12

12. Croughwell N, Newman M, Blumenthal J, White W, Lewis J, Frasco P, et al. Jugular bulb saturation and cognitive dysfunction after cardiopulmonary bypass. Ann Thorac Surg (1994) 58:1702-8. doi:10.1016/0003-4975(94)91666-7

13. Grigore AM, Grocott HP, Mathew JP, Phillips-Bute B, Stanley TO, Butler A, et al. The rewarming rate and increased peak temperature alter neurocognitive outcome after cardiac surgery. Anesth Analg (2002) 94:4-10. doi:10.1213/00000539-200201000-00002

14. Nathan HJ, Wells GA, Munson JL, Wozny D. Neuroprotective effect of mild hypothermia in patients undergoing coronary artery surgery with cardiopulmonary bypass: a randomized trial. Circulation (2001) 104(12 Suppl 1): I85-91. doi:10.1161/hc37t1.094710

15. Boodhwani M, Rubens F, Wozny D, Rodriguez R, Nathan H. Effects of sustained mild hypothermia on neurocognitive function after coronary artery bypass surgery: a randomized, double-blind study. J Thorac Cardiovasc Surg (2007) 134:1443-52. doi:10.1016/j.jtcvs.2007.08.016

16. Lavinio A, Timofeev I, Nortje J, Outtrim J, Smielewski P, Gupta A, et al. Cerebrovascular reactivity during hypothermia and rewarming. Br J Anaesth (2007) 99:237-44. doi:10.1093/bja/aem118

17. Wang B, Armstrong JS, Lee JH, Bhalala U, Kulikowicz E, Zhang H, et al. Rewarming from therapeutic hypothermia induces cortical neuron apoptosis in a swine model of neonatal hypoxic-ischemic encephalopathy. J Cereb Blood Flow Metab (2015) 35(5):781-93. doi:10.1038/jcbfm.2014.245

18. Hogue C Jr, Palin C, Arrowsmith J. Cardiopulmonary bypass management and neurologic outcomes: an evidence-based appraisal of current practices. Anesth Analg (2006) 103:21-37. doi:10.1213/01.ANE.0000220035. 82989.79

19. Urbanski PP, Lenos A, Bougioukakis P, Neophytou I, Zacher M, Diegeler A. Mild-to-moderate hypothermia in aortic arch surgery using circulatory arrest: a change of paradigm? Eur J Cardiothorac Surg (2012) 41:185-91. doi:10.1016/j.ejcts.2011.03.060

20. Goldberg CS, Bove EL, Devaney EJ, Mollen E, Schwartz E, Tindall S, et al. A randomized clinical trial of regional cerebral perfusion versus deep hypothermic circulatory arrest: outcomes for infants with functional single ventricle. J Thorac Cardiovasc Surg (2007) 133(4):880-7. doi:10.1016/j.jtcvs. 2006.11.029

21. Harrington DK, Walker AS, Kaukuntla H, Bracewell RM, Clutton-Brock TH, Faroqui $\mathrm{M}$, et al. Selective antegrade cerebral perfusion attenuates brain metabolic deficit in aortic arch surgery: a prospective randomized trial. Circulation (2004) 110(11 Suppl 1):II231-6. doi:10.1161/01.CIR.0000138945.78346.9c

22. Vuylsteke A, Sharples L, Charman G, Kneeshaw J, Tsui S, Dunning J, et al. Circulatory arrest versus cerebral perfusion during pulmonary endarterectomy surgery (PEACOG): a randomised controlled trial. Lancet (2011) 378(9800):1379-87. doi:10.1016/S0140-6736(11)61144-6

23. Myung RJ, Petko M, Judkins AR, Schears G, Ittenbach RF, Waibel RJ, et al. Regional low-flow perfusion improves neurologic outcome compared with deep hypothermic circulatory arrest in neonatal piglets. J Thorac Cardiovasc Surg (2004) 127(4):1051-6. doi:10.1016/j.jtcvs.2003.11.008

24. Brown MD, Wernovsky G, Mussatto KA, Berger S. Long-term and developmental outcomes of children with complex congenital heart disease. Clin Perinatol (2005) 32(4):1043-57. doi:10.1016/j.clp.2005.09.008

25. Wernovsky G. Current insights regarding neurological and developmental abnormalities in children and young adults with complex congenital cardiac disease. Cardiol Young (2006) 16(1 Suppl):92-104. doi:10.1017/ S1047951105002398

26. Gaynor JW, Stopp C, Wypij D, Andropoulos DB, Atallah J, Atz AM, et al. Neurodevelopmental outcomes after cardiac surgery in infancy. Pediatrics (2015) 135(5):816-25. doi:10.1542/peds.2014-3825

27. Swain JA. Cardiac surgery and the brain. N Engl J Med (1993) 329:1119-20. doi:10.1056/NEJM199310073291511

28. Baumgartner WA, Owens SG, Cameron DE, Reitz BA. The Johns Hopkins Manual of Cardiac Surgical Care. St. Louis: Mosby (1994).
29. Marx JA. Rosen's Emergency Medicine: Concepts and Clinical Practice. 7th ed. Philadelphia: Mosby Elsevier (2010).

30. Greeley WJ, Kern FH, Meliones JN, Ungerleider RM. Effect of deep hypothermia and circulatory arrest on cerebral blood flow and metabolism. Ann Thorac Surg (1993) 56:1464. doi:10.1016/0003-4975(93)90731-V

31. Gaynor JW, Nicolson SC, Jarvik GP, Wernovsky G, Montenegro LM, Burnham NB, et al. Increasing duration of deep hypothermic circulatory arrest is associated with an increased incidence of postoperative electroencephalographic seizures. J Thorac Cardiovasc Surg (2005) 130:1278-86. doi:10.1016/j.jtcvs.2005.02.065

32. Bellinger DC, Wypij D, duPlessis AJ, Rappaport LA, Jonas RA, Wernovsky G, et al. Neurodevelopmental status at eight years in children with dextrotransposition of the great arteries: the Boston Circulatory Arrest Trial. J Thorac Cardiovasc Surg (2003) 126:1385-96. doi:10.1016/S0022-5223(03) 00711-6

33. Churn SB, Taft WC, Billingsley MS, Blair RE, DeLorenzo RJ. Temperature modulation of ischemic neuronal death and inhibition of calcium/calmodulindependent protein kinase II in gerbils. Stroke (1990) 21:1715-21. doi:10.1161/ 01.STR.21.12.1715

34. Chopp M, Knight R, Tidwell CD, Helpern JA, Brown E, Welch KM. The metabolic effects of mild hypothermia on global cerebral ischemia and recirculation in the cat: comparison to normothermic and hyperthermia. J Cereb Blood Flow Metab (1989) 9:141-8. doi:10.1038/jcbfm.1989.21

35. Minamisawa H, Nordstrom CH, Smith ML, Siesjo BK. The influence of mild body and brain hypothermia on ischemic brain damage. J Cereb Blood Flow Metab (1990) 10:365-74. doi:10.1038/jcbfm.1990.66

36. Kuroiwa T, Bonnekoh P, Hossmann KA. Prevention of postischemic hyperthermia prevents ischemic injury of CA1 neurons in gerbils. J Cereb Blood Flow Metab (1990) 10:550-6. doi:10.1038/jcbfm.1990.97

37. Dietrich WD, Busto R, Valdes I, Loor Y. Effects of normothermic versus mild hyperthermic forebrain ischemia in rats. Stroke (1990) 21:1318-25. doi:10.1161/01.STR.21.9.1318

38. Wang B, Armstrong JS, Reyes M, Kulikowicz E, Lee JH, Spicer D, et al. White matter apoptosis is increased by delayed hypothermia and rewarming in a neonatal piglet model of hypoxic ischemic encephalopathy. Neuroscience (2016) 316:296-310. doi:10.1016/j.neuroscience.2015.12.046

39. Mitani A, Kataoka K. Critical levels of extracellular glutamate mediating gerbil hippocampal delayed neuronal death during hypothermia: brain microdialysis study. Neuroscience (1991) 42:661-70. doi:10.1016/0306-4522(91) 90035-M

40. Morikawa E, Ginsberg MD, Dietrich WD, Duncan RC, Kraydieh S, Globus MY, et al. The significance of brain temperature in focal cerebral ischemia: histopathological consequences of middle cerebral artery occlusion in rat. J Cereb Blood Flow Metab (1992) 12:380-9. doi:10.1038/jcbfm.1992.55

41. Chopp M, Welch KM, Tidwell CD, Knight R, Helpern JA. Effect of mild hyperthermia on recovery of metabolic function after global cerebral ischemia in cats. Stroke (1988) 19:1521-5. doi:10.1161/01.STR.19.12.1521

42. Parr GV, Blackstone EH, Kirklin JW. Cardiac performance and mortality early after intracardiac surgery in infants and young children. Circulation (1975) 51:867-74. doi:10.1161/01.CIR.51.5.867

43. Shi S, Zhao Z, Liu X, Shu Q, Tan L, Lin R, et al. Perioperative risk factors for prolonged mechanical ventilation following cardiac surgery in children and young infants. Chest (2008) 134:768-74. doi:10.1378/chest.07-2573

44. Wernovsky G, Wypij D, Jonas RA, Mayer JE Jr, Hanley FL, Hickey PR, et al. Postoperative course and hemodynamic profile after the arterial switch operation in children and infants. A comparison of low-flow cardiopulmonary bypass and circulatory arrest. Circulation (1995) 92:2226-35. doi:10.1161/01. CIR.92.8.2226

Conflict of Interest Statement: The authors declare that the research was conducted in the absence of any commercial or financial relationships that could be construed as a potential conflict of interest.

Copyright (c) 2016 Bhalala, Appachi and Mumtaz. This is an open-access article distributed under the terms of the Creative Commons Attribution License (CC BY). The use, distribution or reproduction in other forums is permitted, provided the original author(s) or licensor are credited and that the original publication in this journal is cited, in accordance with accepted academic practice. No use, distribution or reproduction is permitted which does not comply with these terms. 